MAEM

1,1

\section{0}

Received 4 June 2018 Accepted 17 July 2018

\title{
Recent advances in international marine econometrics
}

\author{
Yin Kedong and Li Xuemei \\ School of Economics, Ocean University of China, Qingdao, China and \\ Marine Development Studies Institute of OUC, \\ Ministry of Education, Key Research Institute of Humanities and \\ Social Sciences at Universities, Qingdao, China
}

\begin{abstract}
Purpose - Since 2000, China, along with the USA, UK, France, Japan and many other developed countries have drawn up new blueprints for the development of a marine economy. At present, international marine economics research has entered into a new period of development, and the research methods of ocean econometrics are becoming more complex and mature. The purpose of this paper is to review the progress of international marine econometrics research and gives the development direction of marine econometrics.

Design/methodology/approach - The Web of Science core collection database was utilized, harvesting data from 1996 to May 2018, measuring the marine economy research from 1,489 articles as its sample, using CiteSpace visualization analysis tools.

Findings - Mapping the knowledge map from annual international marine economic metrology, literature identification, keywords, involving disciplines and related journals, countries (regions) and research and analyzing the research status of reveals the research frontiers of international marine economy measurement (learning) by using CiteSpace.

Originality/value - The conceptions and characteristics of marine econometrics are defined and analyzed, and the theoretical method of marine econometrics is sorted out. Mapping the knowledge diagram of marine econometrics and discussing the research status of international marine economics, and clarifying the existing problems, future opportunities and challenges of international marine econometrics research.
\end{abstract}

Keywords Marine economy, Marine econometrics, Knowledge map, Analysis of frontier hot spots

Paper type Research paper

\section{Introduction}

Marine economy was bred out of the rapid development of marine practice exploration and the in-depth study of marine economic theory. It plays an important role in stimulating economic growth, creating a large number of employment opportunities, and promoting the economic and social development of all countries. At present, scholars have achieved rich research results in the field of marine economy (Rorholm, 1967; Moller and Fitz, 1994; Pugh and Skinner, 1996, 2002; Pugh, 2008). With the deepening of scientific research, the study of marine economics has also entered a new stage of quantification: microcosmic and scientific research.

Marine econometrics (scientific analysis) is a methodological estimation system that uses economic theory, statistics and mathematical methods to reveal causal relationships among various factors entailed in ocean economic phenomena. Pontecorvo et al. (1980) used the national accounts method to study the contribution of the marine sector to the US economy from an industrial perspective, making the quantitative analysis method an effective means of marine economic evaluation. Jiang (1990) used this quantitative method to predict the development trend of China's marine economy, and introduced econometrics into the field of marine economic research, in order to explore the causal relationship and related

(c) Yin Kedong and Li Xuemei. Published in Marine Economics and Management. Published by Emerald Publishing Limited. This article is published under the Creative Commons Attribution (CC BY 4.0) licence. Anyone may reproduce, distribute, translate and create derivative works of this article (for both commercial and non-commercial purposes), subject to full attribution to the original publication and authors. The full terms of this licence may be seen at http://creativecommons.org/licences/by/4.0/legalcode 
relationship of ocean economic variables. Since then, more and more scholars have applied marine economics to more specific areas of marine research. Some scholars also applied the econometric method to marine resources and environment, and other fields. Bhat (2003) used LIMDEP software program, employing random effects of a Poisson regression model with panel data, estimating the economic benefits of improved fish stocks and coral reefs found in the Florida Keys. Barbier et al. (2013) found that coastal wetlands and their vegetation have significant effects on reducing storm surge problems through regression analysis. Gröger et al. (2011) used econometric methods to analyze the potential changes generated by marine ecosystems. Liu et al. (2017) and Cao et al. (2005) revealed the structural characteristics of regional marine economy and the basic laws of its evolution through quantitative analysis. He et al. (2014) and Zhao and Yong (2017) collected economic cross-regional panel data integrated both for China's coastal regions, using time-series and spatial measurement methods to explore the characteristics and laws of coastal economic development.

Along with the deepening of this sort of research, more econometrics methods are now being widely applied in the study of marine economics. Jin et al. (2003) established the inputoutput model of coastal zone economy based on relevant data pertaining to the marine food chain, and conducted joint analysis and research on the marine economy and ecosystem. Li et al. (2015) used the DEA index to decompose the total factor productivity of China's coastal marine economy. Zamani et al. (2008) predicted how ocean energy, ocean wind energy and tidal energy could be effective by means of machine learning algorithms and artificial neural networks. Di et al. (2012) combined social, economic, resource, environmental and other factors to establish a system-dynamic model for the sustainable development of a marine economy. Yuan et al. (2013) used the multivariate gray model to study the trends of China's marine economic production, employment and their interactions based on the scarcity and uncertainty of ocean economic data. Feng and Du (2014) used the gray correlation method to analyze the relationship between financial support and the development of the marine economy.

However, due to the single use of methods, there are some limitations in the study. In order to make the research results pertaining to the marine economy more scientific and rigorous, many scholars have used various methods to solve its more practical problems. Zhang and $\mathrm{Hu}$ (1997) first used a variety of econometric models to study marine economic problems, using a linear programming model, an analytic hierarchy process (AHP), a gray correlation model, principal component analysis, cluster analysis and system dynamics, he studied the economic development of long mountain islands. Yin and Ma (2010) selected ten warning indicators for the development of China's marine economy for the first time, using mathematical methods and empirical analysis, to determine the threshold of early warning indicators, designed to build China's marine economic cycle fluctuation early warning signal system. On this basis, Yin and Li (2011) comprehensively used entropy value method, principal component analysis method, gray correlation analysis method and AHP to evaluate the comprehensive strength of China's coastal marine economy. Lee et al. (2017) used fuzzy target programming, applying econometrics to the field of ocean energy. Nursey-Bray et al. (2018) used the AHP and semi-structured methods to assess the marine aquaculture industry in South Australia.

As described in the aforementioned literature, marine economic quantitative research in the 1970s-1990s was in its initial development period, mainly focusing on empirical analyses, inductive analyses and qualitative analyses, Nonetheless, quantitative analysis of the marine economy is still very weak, the study of marine econometrics has not been presented. In the late 1990s, especially since 2000, the research achievements of marine econometrics in the field of traditional marine economics have been increasing gradually. In recent years, marine econometrics has had many research objects and a wide range of research methods, but there is still no summary of research progress and research frontiers. In order to facilitate the understanding and study of the relevant methods of marine 
MAEM

1,1

22

econometrics, this paper introduces its concept, theory and method system in detail, using the bibliometric method to study its results and adopts the method of the literature's metrology to ocean to quantify the results of econometric analysis, with the help of a knowledge map that is shown visually in the form of more international research status and research situation of the marine econometrics. The frontiers and focuses of marine econometrics in the field of mining provide a new way of thinking. The remaining part of this paper is organized as follows: the second part explains the understanding and thinking of scholars about the concept definition, theoretical system, method system and other basic problems of marine econometrics. The third part uses a bibliometric method to analyze the research status of the discipline. The fourth part looks forward to future research directions for the field. The fifth part summarizes the entire paper.

\section{Marine econometrics architecture}

\subsection{The concept and characteristics of marine econometrics}

Marine econometrics is an applied technology and method discipline within the field of scientific research pertaining to marine economics. Economic theory, the theory of marine science, econometrics theory and the actual statistical data as its foundation, plus its corresponding use of mathematics, statistics, computer technology, as well as the methods of system theory, information theory, cybernetics, marine econometric modeling that serve as the principal means of quantitative analysis with stochastic characteristics of marine economic variables, of technical method toward a general designation (discipline). Including regression analysis, input and output, time-series analysis, operational research, game theory, equilibrium theory, neural network technology, system dynamics and other aspects, marine science is coming into its own as an advanced scientific endeavor.

Marine econometrics focuses on the research into, and application of, various quantitative economic analysis methods. Its outstanding features are optimization, quantification and practicality, and regards optimization as the starting point for studying the basic laws of the marine economics, and then studies the interrelationship, influence, role, and trend of various factors in the marine economy. This research object determines its quantitative and practical chemistry characteristics, thus providing tools and powerful methodological support for the study of various marine economic issues.

\subsection{The theoretical system of marine econometrics}

2.2.1 Disciplinary basis of marine econometrics. The combination of marine science and economics gave birth to marine economics. The combination of statistics, mathematics and economics gave rise to econometrics. With the integration of marine economics and econometrics, the problems in marine economics are studied by means of econometrics, which gradually produces marine econometrics. Therefore, marine economics especially in marine science, statistics, mathematics, economics and management science use such disciplines for its foundation, while at the same time drawing on and assimilating the game theory, systems theory, information theory, cybernetics, and computer technology and decision-making method of optimization theory, etc.

2.2.2 Subjects and methods. Research objects: it mainly studies the quantitative relationship or rule between various variables in oceanic or related economic activities.

Research methods: based on econometrics, at the same time absorbing ocean science, computer science, system science, environmental science, life sciences and other related disciplines in its method, and the overall discipline is improved to adapt to the characteristics of marine economy research.

2.2.3 Research purposes and application areas. In marine economic activity analysis, the quantitative relationship between variables from the perspective generated by empirical 
exploration of marine economics operations and law, enriching the discipline's theory, marine economic structural analysis, marine economic forecasts, marine economic policy evaluation, along with testing and development of marine economic theory, etc. In so doing, a theoretical basis for the development of marine economic policy may be provided, thus promoting sustained, stable and healthy development of the marine economy.

Main applications include: marine industrial structure, marine consumption structure and marine investment structure; marine economic situation prediction, monitoring and warning with respect to the marine economy, sustainable development of the marine economy; assessment of comprehensive marine strength, integration of land and sea economy; integration of the ocean economy and development of ocean science and technology; the evolutionary process of the marine economy and marine industry.

\subsection{A system method of marine econometrics}

For marine economic development, human for marine economy research has been applied more to the latter field than land economics, given that marine econometrics research methods are principally derived from the research method of econometrics modeling. The research methods of marine econometrics mainly devolve from quantitative economic analysis. It can also be divided into either broad and narrow methods, or classical and non-classical ones.

2.3.1 Classical and non-classical marine econometrics. The classical method of marine econometrics is mainly borrowed from the econometrics methods developed and widely used before the 1970s. Those models include single variable linear regression, multiple variable linear regression, relaxation of basic assumptions, simultaneous equations and so forth.

The non-classical method of marine econometrics mainly refers to work done after the 1970s developed econometrics methods, and mainly includes: the variable parameter model, the non-linear and discrete choice model, the panel model, the time-series model and limited dependent variable model, among others.

2.3.2 Generalized and narrow sense of marine econometrics. In a narrow sense, the method of marine econometrics reveals the causality between various factors in phenomenon pertaining to the marine economy by establishing a model of marine econometrics and using a regression method. In a narrow sense, the ocean econometric model includes: the classic ocean econometric model and the non-classical ocean econometric one.

The generalized method of marine econometrics is a broad term referring to the quantitative analysis of marine economic phenomena using economic theory, statistics and mathematical methods. It mainly includes: the classical econometric model and cycle theory, growth theory, optimization theory, decision-making science, wavelet theory and game theory, along with the input-output model, system simulation and methods such as those found in the DEA, CGE and DSGE models.

\section{Knowledge map analysis of the current situation of marine econometrics}

\subsection{Analysis of the development trend of marine econometrics}

The data sample utilized for this article were taken from the Web of Science core collection database. Through employing a search using the keyword "marine economy," the data were found. The time period selected was from 1996 to May 2018, and an exact matching search was conducted. A total of 3,075 search results were obtained. Further screening and sorting of the search results such as "regression analysis, time series, parameter test and measurement model," revealing 1,489 articles on marine econometric research, through May 30, 2018. The number of documents published as marine econometrics research in 2018 was 128 .

In order to statistically analyze the research trends of marine econometrics, this paper summarizes the number of documents published in marine econometrics and the econometrics methods used in the literature. Figure 1 depicts the quantitative distribution of 
MAEM

1,1

24

Figure 1.

Number of published documents in the field of marine econometrics from 1996 to 2018

Figure 2.

Number of published documents for methods used in marine econometrics studies from 1996 to 2017 the literature on marine econometrics from 1996 to 2018. The number of publications in 2018 was forecasted from the number of published documents in the first five months of 2018 and the trends found in 2000-2017 publications, indicated by the dotted line; Figure 2 summarizes the measurement methods used in marine econometrics study from 1996 to 2017 and the number of publications per year.

It can be seen from Figure 1 that the number of papers published in marine econometrics has experienced a slowly increasing trend - yet increasing more rapidly lately, indicating that marine econometrics research has gradually received the attention and attention of scholars.

First, from the slow increase to the gradually increasing phase (2000-2010): this stage is the initial stage of ocean econometrics, mainly the attempted application of econometrics methods in the field of marine economic research. This stage mainly sorted out the concepts and theories of marine economics and quantitative analysis, focusing on structural analysis, policy evaluation and trend analysis. While it was based on qualitative analysis, such as empirical analysis and inductive analysis, its use of different empirical and quantitative analysis methods, such as regression analysis, principal component analysis, gray correlation analysis, system simulation and even input-output and linear programming, had begun to increase. The research samples are mainly based on cross-sectional data and a small amount of time-series data. The above two periods belong to the classical macroscopic
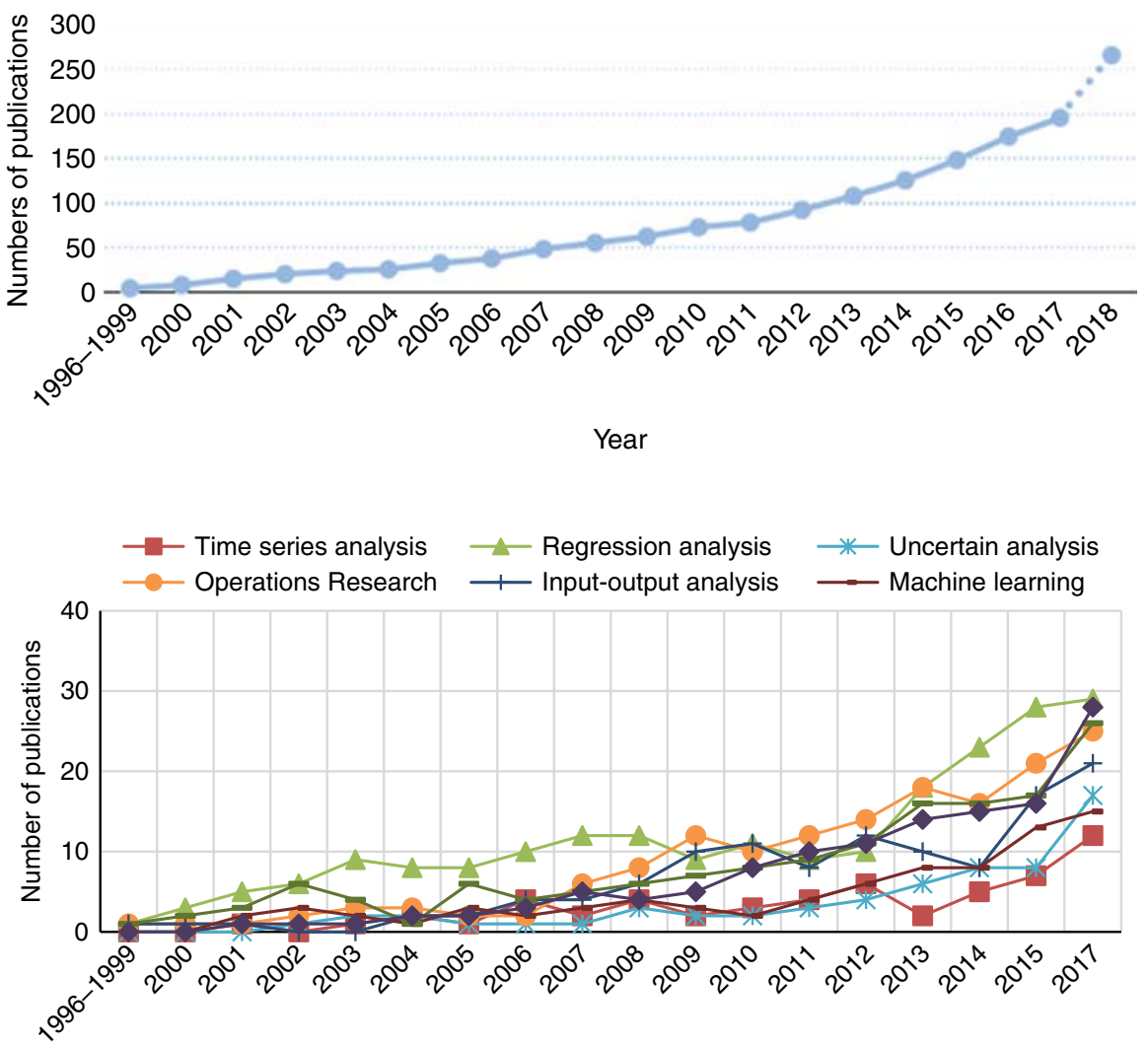

YEAR 
analysis and research stage of marine economy. Based on traditional economic theory, the classical and macroscopic ocean economy is analyzed and evaluated, and marine econometrics research thus began to sprout. The 2000s were an important period for the study of marine econometrics. It was essentially different from the quantitative study of marine economy before 2000. Therefore, we generally believe that 2000 is the base year of marine econometrics research, and may therefore be called the "first year."

Second, gradual growth-rapid growth stage (2010-2017): the research utilizing marine econometrics at this stage is gradually increasing, and marine economic issues involved are more specific, and the application methods are more extensive and complex. The quantitative analysis methods and their frequency of use in relevant research results increased significantly, especially from what was seen in the marine industry, economic forecasts, structural evolution, sea-land integration, sustainable development, marine comprehensive strength assessment, marine economic cycle fluctuations, marine disaster loss assessment, etc.; the research content of the marine econometrics expanded rapidly. Qualitative analysis, such as empirical and inductive analysis, was gradually reduced. Regression analysis, principal component analysis and analytic hierarchy analysis were widely used. There were more empirical analyses of distributed lag regressions, panel data models and spatial measurement. Intermediate time-series models, such as traditional timeseries models and panel models, were rapidly popularized and research samples, such as cross-section data, time-series data and panel data were continuously expanded.

Third, at present, although still dominated by classical macroscopic ocean economic analysis research, guided by traditional economic theory and structural modeling, the research field has been deepened from the macro (i.e. country) level to mid-level (i.e. provincial and municipal), and the application of modern econometrics methods has gradually increased. Decision optimization methods, system dynamics, input-output models, etc., are widely used, and the application of machine learning algorithms, uncertainty analysis methods and time-series methods also have a clear upward trend. Furthermore, the quantitative analysis of marine economic research is no longer limited to the traditional econometrics method, but instead involves characteristics from multiple methods. The objects and fields of marine economic research also tend to be mesoscopic and microscopic, and the research fields have mainly expanded into industrial structure, time-varying characteristics, spatial structure and regional competitiveness. The iconic research results have grown rapidly, and the quality of research results has been continuously improved. Marine econometrics research has been in a period of rapid development, and its theoretical, method, and application systems have matured.

Combining the above document distribution, a pie chart showing the application of marine econometrics method from 1996 to 2018 may be plotted (Figure 3). In studies of

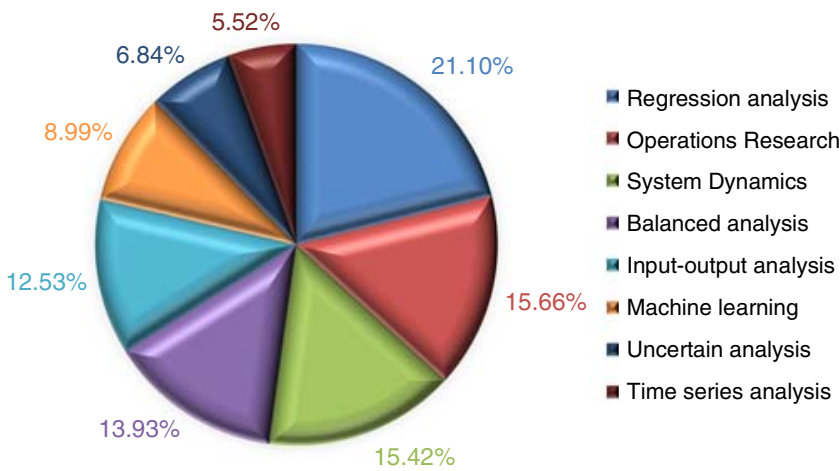

International marine econometrics
Figure 3.

Proportion of marine econometrics algorithms from 1996 to 2018 
MAEM

1,1

26

marine economics from 1996 to 2018, regression analysis was still the main analytical method, accounting for 21.10 percent of all studies. Operational research methods, system dynamics, equilibrium theory and input-output methods have shown high growth in the application of marine economics, accounting for 15.66, 15.42, 13.93 and 12.53 percent, respectively. Although machine learning algorithms, uncertain methods, and time-series methods account for a relatively small proportion of them (8.99, 6.84 and 5.52 percent, respectively), they have shown significant advantages.

The application of marine econometrics methods has accounted for 45 percent of marine economic research. Figure 4 shows the number of marine economic research literature appearances from 1996 to 2017, plus those of the marine econometrics research variety, and their proportions. Figure 5 shows the growth rate curve for the number of marine econometrics articles appearing in the literature from 2000 to 2017.

As can be seen in Figure 4, the amount of literature pertaining to marine economics research, and marine econometrics research, shows a significant upward trend. Moreover, since 2010, the proportion of literature about marine econometrics research has been continuously increasing - by more than 55 percent in 2017. As observed in Figure 5, the growth rate in the ocean economics research literature calculated by the chain growth measurement method has maintained its high-speed growth. On the whole, the growth rate of literature on marine econometrics had enjoyed rapid growth in the early period due to the small number of articles, then the research tended stabilize after 2011 with the annual growth rate of the number of new articles reaching around 15 percent, which means marine econometrics has become dominant in the field of marine economics research methodology.

Figure 4.

The number of marine economic research documents, the number of marine econometrics research documents and the change curve of their proportion from 1996 to 2017
Figure 5.

The growth rate curve of the research literature on marine econometrics from 2000 to 2017
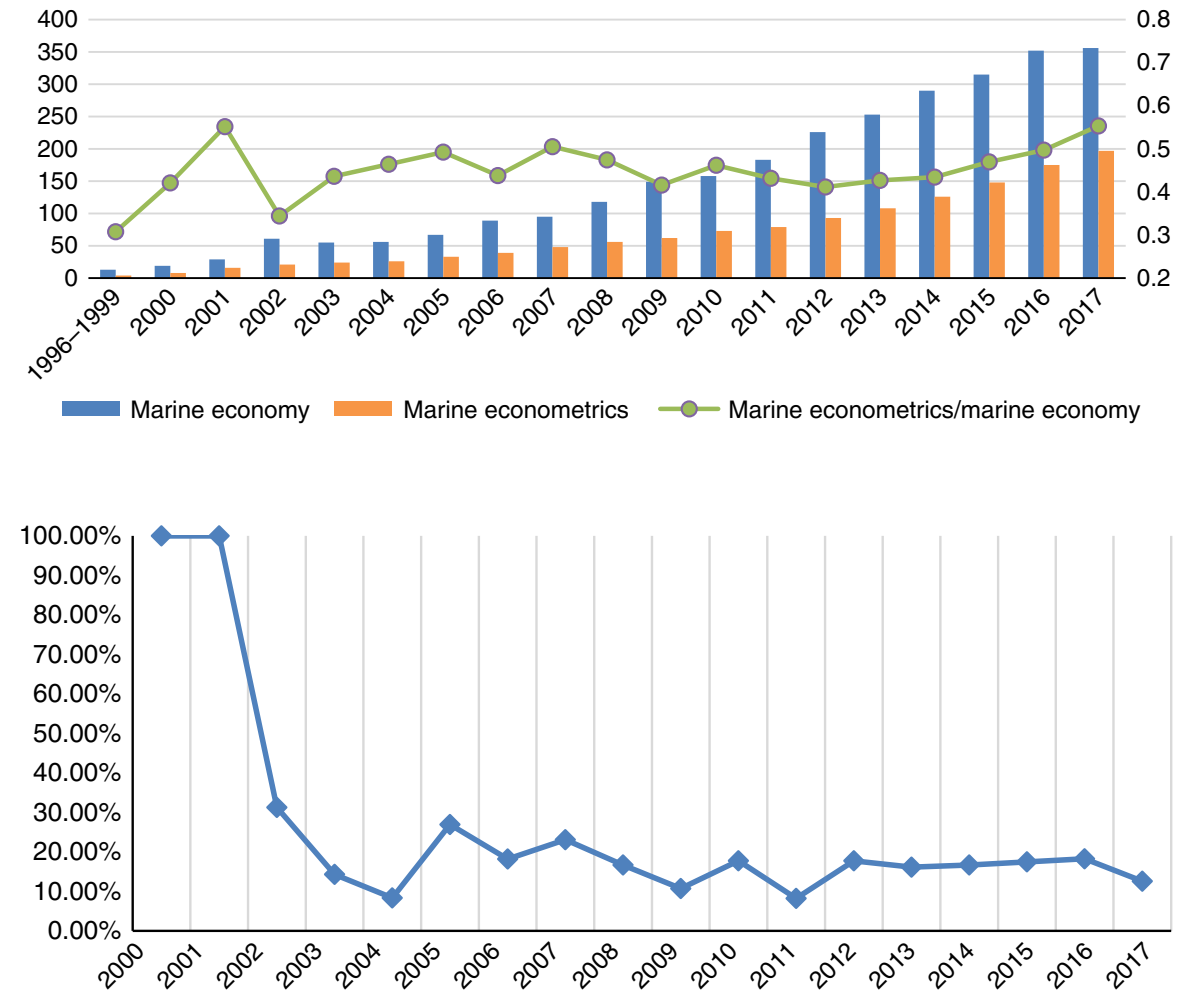
In addition, this paper also reports the results of searches in the CNKI database for 6,380 Chinese articles on the marine economics reached between 2001 and May 2018, obtaining 1,008 references involving marine econometrics, then draws the scale map of the Chinese literature on marine econometrics from 2001 to 2018, as shown in Figure 6.

Contrasting Figures $4-6$, although there is a large number of literature about marine economics studied by Chinese scholars, but the proportion of marine econometrics articles is low, suggesting that Chinese scholars concentrate less on marine economics quantitative research, rather focusing on the qualitative analysis of the marine economy with descriptive language. And many low-level repeated Chinese studies on marine economics may not be excluded, and even then there are gaps among the literature in terms of depth and breadth, the quality and the research methods, innovation and internationalization, and so on.

\subsection{The analysis of keywords of marine econometrics}

It was based on the sample source obtained from the Web of Science, retrieving 1,489 records related marine econometrics papers, and generating a keyword map (Figure 7) through using CiteSpace software to extract the keywords after analyzing the literature.

From the perspective of knowledge theory, the higher the degree and frequency of keywords, the more concentrated the problems that international scholars have been paying attention to (for a significant period), i.e., the research hotspots in the field. And the center degree of keywords is calculated through the common keyword in the literature and is
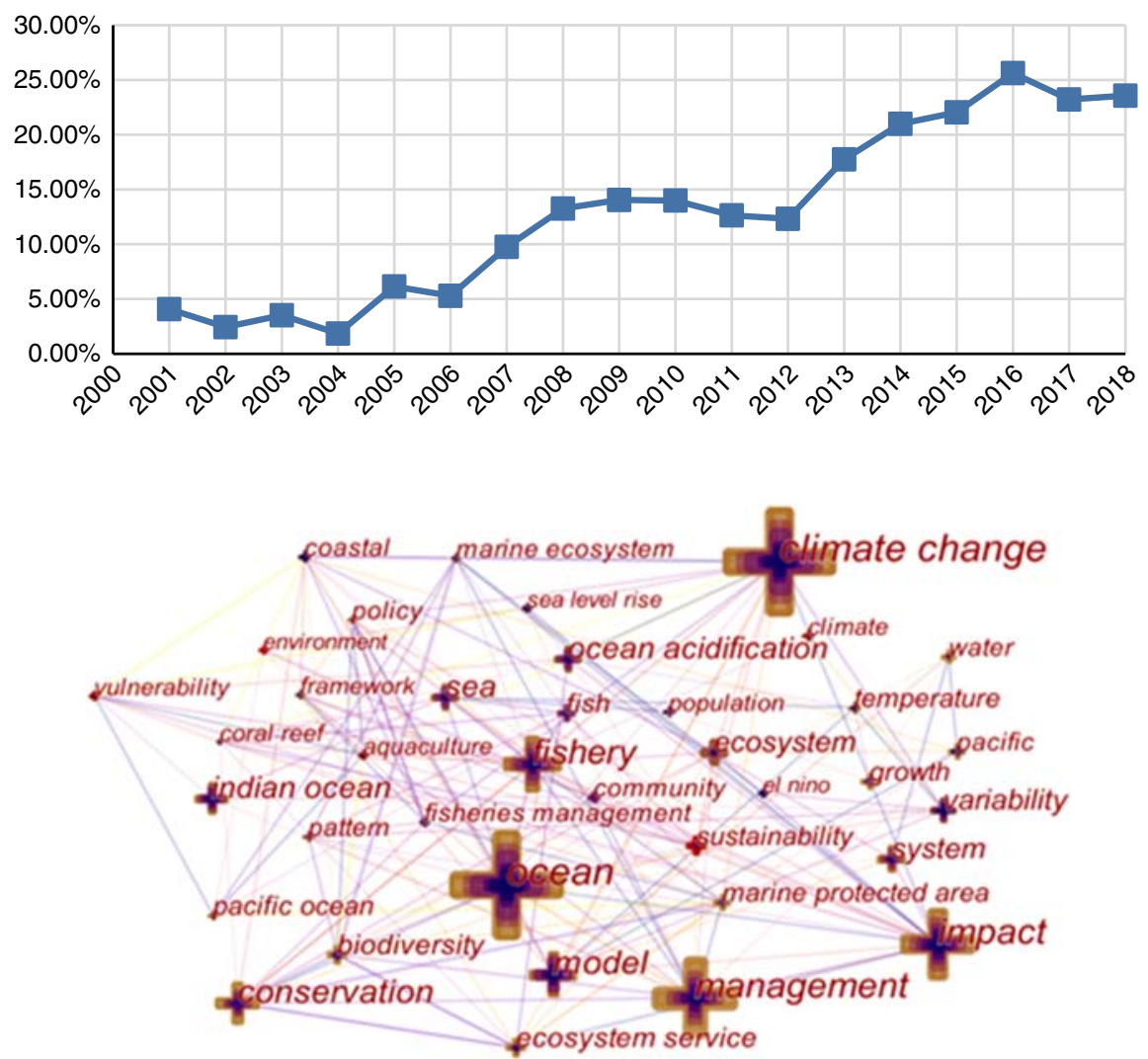

International marine econometrics

Figure 6.

A scale map of the Chinese literature on the study of marine econometrics from 2001 to 2018
Figure 7.

Keywords map of ocean econometrics 
MAEM

1,1

28

Table I.

The twelve keywords with the highest frequency that appeared in marine econometrics studies stronger than 0.1 , which means there are more studies conducted through this point then has a strong influence. Therefore, in this paper, hot keywords with high centrality and frequency and some data are selected as shown in Table I.

As can be seen from Figure 7 and Table I, the distribution of structural characteristics of keywords in international marine econometrics is as follows:

From the central node, after eliminating high-frequency keywords themes, "ocean" (0.11), "climate change" $(0.22)$ is the highest keywords in the centricity (brackets for the centricity, similarly hereinafter), which means that "climate change" is the most influential word besides "ocean." In addition, "model" (0.14), "impact" (0.11), "fishery" (0.11) and "sustainability" (0.1) are also ranked the front of the central keywords, which has a certain influence through these keywords to study.

From the frequency of nodes, climate change is still the keyword with the highest frequency except thematic words, appearing 206 times. In addition, "management," "impact," "fishery," "model," "conservation" and "Ocean acidification" are also frequent keywords. Combining the nodes centrality analysis, marine econometrics research and "ocean environment," "fishing," "model" is closely related to, which is the hot research direction of the study of ocean econometrics.

\subsection{The analysis of related disciplines in marine econometrics}

Figure 8 was generated using the CiteSpace domain analysis consisting of 1,489 literature retrieval results for marine econometrics, in which the more frequently the subject belongs to, the

\begin{tabular}{llccclcc}
\hline Rank & Keyword & Frequency & Centrality & Rank & Keyword & Frequency & Centrality \\
\hline 1 & Ocean & 214 & 0.11 & 7 & Conservation & 91 & 0.07 \\
2 & Climate change & 206 & 0.22 & 8 & Ocean acidification & 64 & 0.06 \\
3 & Management & 154 & 0.09 & 9 & Biodiversity & 44 & 0.09 \\
4 & Impact & 142 & 0.11 & 10 & Sustainability & 40 & 0.10 \\
5 & Fishery & 115 & 0.11 & 11 & Marine protected area & 39 & 0.06 \\
6 & Model & 95 & 0.14 & 12 & Pollution & 18 & 0.09 \\
\hline
\end{tabular}

Figure 8.

Related fields of marine econometrics

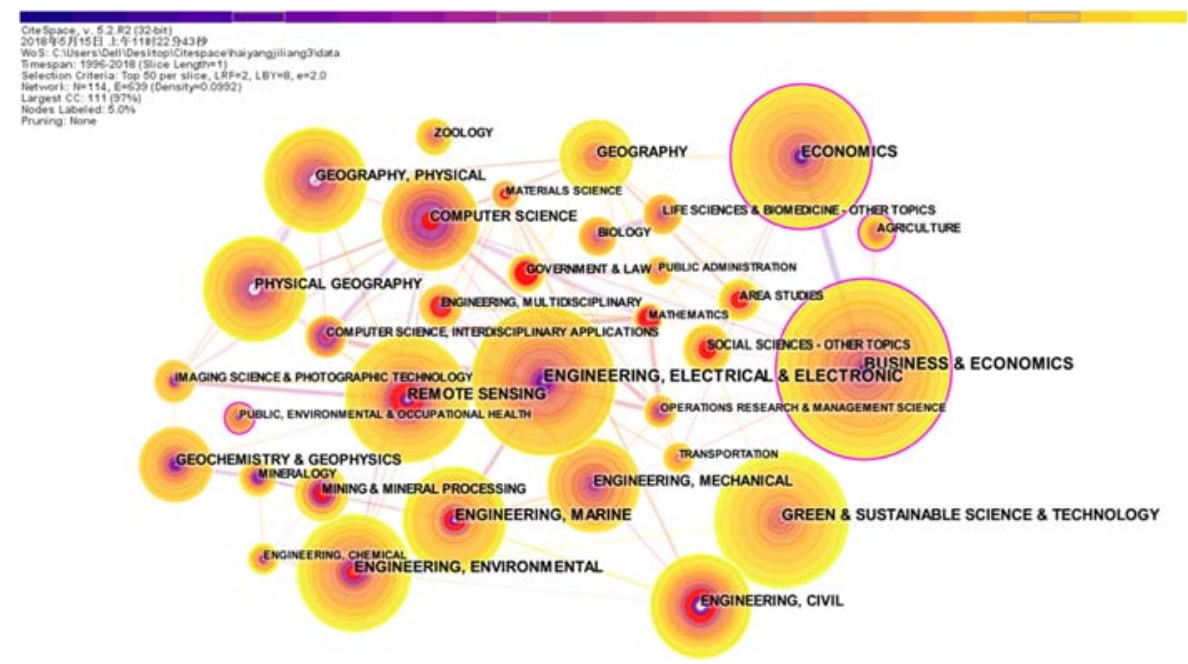


bigger the nodes are in the map. There are 114 nodes, 639 connections and the network density is 0.0992 in the Figure 8. The node label represents the discipline of the document; the circle color represents the time of posting, with lighter colors indicating closer times of posting; the node diameter is positively correlated with the amount of papers issued by the subject; the thickness of the connection between nodes reflects the strength of the cooperative relationship between them, and the parts of the node periphery surrounded by a purple ring suggest that wide connections exist between one node and others in different research fields, which often make up the hubs of discipline or knowledge domains, having special significance in the node network.

Figure 8 indicates that the study of marine econometrics involves many disciplines and is widely used in applied disciplines and interdisciplinary subjects, relatively speaking. The larger points in the figure indicate that the subject has a higher frequency of citations, and the denser points indicate that the subject is more central. It can be seen from the figure that marine econometrics is closely related to Business \& Economics, Economics, Mathematics, Social Science and other disciplines. Meanwhile, the method of marine econometrics is also applied to Geography, Physical Geography and other geographical disciplines. In addition, marine econometrics is also used for the analysis of Engineering, Environmental Science, Green \& Sustainable Science \& Technology and other disciplines. The largest node in the figure is Business \& Economics, which is ranked first, boasting a frequency of 109. From the ring of the node, the thickness of the annual ring is gradually increasing, indicating that the number of times it is cited has increased gradually over time. Among the many connections to the Business \& Economics node, the deepest and thickest one points to Economics, which was cited 87 times. As can be seen from the connection, these two disciplines have a strong co-citation relationship. In addition, the periphery of these two nodes is surrounded by purple rings, indicating that these two nodes are key points, which play an important role in the transformation of the entirety of marine econometrics. Engineering, Electrical \& Electronic was cited 92 times, indicating that the marine econometrics method can be used in electrical engineering, which has close links with Engineering, Marine, Operations Research \& Management Science, Computer Science and Information Systems. Another significant node is Green \& Sustainable Science \& Technology, which was cited 85 times, indicating that the marine econometrics method is a hot research method in the research fields for green and sustainable development.

\subsection{Analysis of published journal articles of marine econometrics}

The CiteSpace software was used to visually analyze the journal data pertaining to 1,489 documents from 1996 to 2018, generating Figure 9.

In Figure 9, there are 132 nodes and 607 links with a network density of 0.0702 . The size of the nodes in the figure indicates the amount of papers in the journal, and the journals with higher volumes reflect the knowledge and attributes of marine econometrics, which can provide researchers with the clearest research connotations. The denser the connection between the node and other nodes, the stronger the centrality of the node, meaning that the node belongs to the classic journal subset and has the support of the knowledge base in the relevant research field. The journals that publish the most relevant literature on marine econometrics are listed in Table II. The 18 journals in Table II cover a wide range of fields. Ocean \& Coastal Management, Journal of Environmental Management and Environmental Management are important journals in Environmental Management. Marine Policy and Ecological Economics belong to journals in the field of marine economics. Journal of Fluid Mechanics is a mechanical engineering journal, and Nature is a comprehensive international science and technology journal. It can be seen from these facts that marine econometrics is a multidisciplinary, interdisciplinary subject, which contains the characteristics of economy, management, environmental science, engineering, and many other disciplines. Among them, Ocean \& Coastal Management published around 93 articles, and Marine Policy ranked second with 76 articles. Among them, Ocean \& Coastal Management published up to 


\section{MAEM \\ 1,1}

30

Figure 9.

Distribution charts of published journals published in marine econometrics

$\longrightarrow$

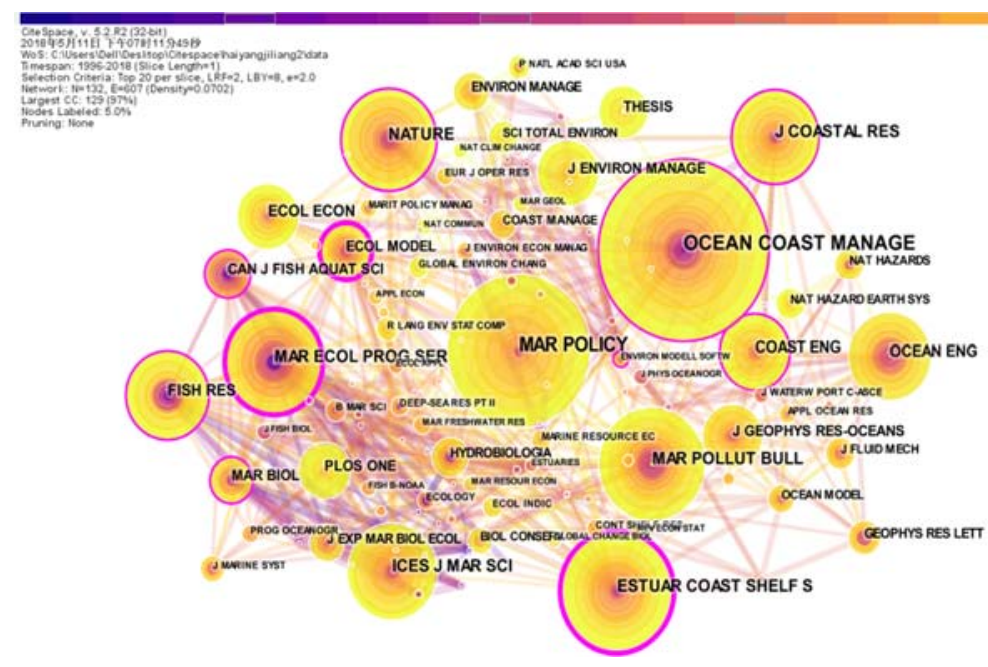

\begin{tabular}{|c|c|c|c|c|c|c|}
\hline Rank & Journal & Frequency & Centrality & $\begin{array}{c}\mathrm{IF} \\
(2016)\end{array}$ & Index & Q \\
\hline 1 & Ocean \& Coastal Management & 93 & 0.12 & 1.861 & SCIE & Q4 \\
\hline 2 & Marine Policy & 76 & 0.04 & 2.235 & SSCI & Q2 \\
\hline 3 & Estuarine Coastal and Shelf Science & 60 & 0.15 & 2.176 & SCI & Q3 \\
\hline 4 & Marine Pollution Bulletin & 58 & 0.11 & 3.146 & $\mathrm{SCI}$ & Q3 \\
\hline 5 & Nature & 57 & 0.05 & 40.137 & SCI & Q1 \\
\hline 6 & Marine Ecology Progress Series & 52 & 0.13 & 2.292 & $\mathrm{SCI}$ & Q3 \\
\hline 7 & Fisheries Research & 51 & 0.09 & 2.185 & SCIE & Q2 \\
\hline 8 & Ices Journal of Marine Science & 49 & 0.17 & 2.760 & SCI & Q2 \\
\hline 9 & Ocean Engineering & 49 & 0.01 & 1.894 & $\mathrm{SCI}$ & Q3 \\
\hline 10 & Journal of Coastal Research & 47 & 0.17 & 1.915 & SCI & Q4 \\
\hline 11 & Canadian Journal of Fisheries and Aquatic Sciences & 41 & 0.09 & 2.466 & SCI & Q2 \\
\hline 12 & Coastal Engineering & 41 & 0.13 & 3.221 & SCI & Q2 \\
\hline 13 & Journal of Geophysical Research-Oceans & 40 & 0.05 & 2.939 & $\mathrm{SCI}$ & Q2 \\
\hline 14 & Ecological Economics & 37 & 0.06 & 2.965 & SCI & Q3 \\
\hline 15 & Ecological Modeling & 35 & 0.17 & 2.363 & $\mathrm{SCI}$ & Q3 \\
\hline 16 & Journal of Environmental Management & 34 & 0.01 & 4.010 & SCI & Q2 \\
\hline 17 & PLOS ONE & 33 & 0.02 & 2.806 & $\mathrm{SCI}$ & Q2 \\
\hline 18 & Environmental Management & 30 & 0.09 & 1.878 & SCI & Q3 \\
\hline
\end{tabular}

93 articles, and Marine Policy ranked second with 76 articles. In addition, journals such as Ocean \& Coastal Management, Estuarine Coastal and Shelf Science, Marine Ecology Progress Series, Ices Journal of Marine Science, Journal of Coastal Research, Coastal Engineering, and Ecological Modeling have high intermediaries. The literature in such journals represents a certain degree of emphasis in the field of marine economics research and has important academic contributions.

\subsection{Analysis of national (regional) institutions for marine econometrics research}

According to the 1,489 document data records retrieved, the country (region) information of the author was read and summarized. Authors from 71 countries/regions were found to 
have studied marine econometrics, and selected 29 countries with high frequency of occurrence to establish correlations, as shown in Figure 10.

In Figure 10, the circle of nodes represents the country or region, and the size of the circle corresponds to the number of articles published in the country or region. The more published in the region, the larger the circle. In Figure 10, the USA is in the largest circle, indicating that the USA has the largest number of published articles on marine econometrics. The connection between nodes represents the cooperation relationship between two countries or regions with links. The density of the network indicates the closeness of cooperation among scholars in various countries or regions. Generally speaking, the higher the density of the network, the closer the cooperation between scholars from various countries or regions engaged in marine econometrics. As can be seen from Figure 10, the cooperation between European countries or regions is relatively close, while that between Asian countries is less so.

Table III summarizes the centrality of the top 20 countries or regions with high frequency of occurrence. The information is calculated according to the country or region of the author. Since there are often multiple authors of a single article, the sum of the frequencies of the countries or regions statistics sum to a number greater than 1,489. From Table III, one may see that four countries - the USA, China, the UK and Australia - have produced the most studies about marine econometrics. Among those four, the frequency of the emergence of American scholarship is up to 581 - far beyond that of other countries. Scholars in China, Britain and Australia also have provided rich research on marine econometrics. However, their centrality is not high, indicating that they mainly focus on the study of marine economic problems in their respective regions, and they do not strongly cooperate with other regional authors. Some European countries, such as France, Spain, Italy and Norway, have a higher degree of centrality, indicating that the scholars in these countries pay more attention to the cooperation between countries and regions, and the content of their research is more extensive.

In order to better understand the distribution of research institutions in marine econometrics from 1996 to 2018, we analyzed 1,489 observations through the CiteSpace software, established a correlation network between research institutions, and plotted the map shown in Figure 11.
International marine econometrics

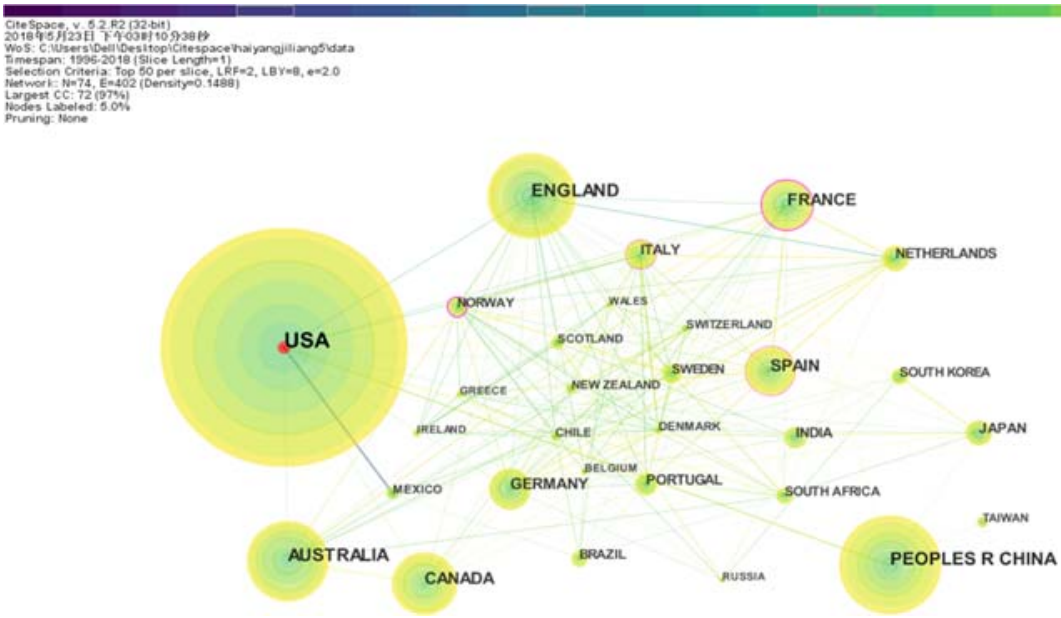

Figure 10.

Network of cooperation between the 29 countries with the largest number of marine econometrics publications from 1996 to 2018 


\begin{tabular}{lllcc}
\cline { 2 - 4 } MAEM & \multicolumn{1}{c}{ Country } & Frequency & Centrality \\
\cline { 2 - 5 } & Rank & USA & 581 & 0.07 \\
& 1 & People's Republic of China & 239 & 0.06 \\
& 2 & England & 209 & 0.07 \\
$\mathbf{3 2}$ & 3 & Australia & 191 & 0.05 \\
& 4 & Canada & 152 & 0.05 \\
& 5 & France & 121 & 0.27 \\
& 6 & Spain & 118 & 0.13 \\
& 7 & Germany & 102 & 0.05 \\
& 8 & Italy & 77 & 0.17 \\
& 9 & Japan & 57 & 0.01 \\
& 10 & The Netherlands & 66 & 0.04 \\
Table III. & 11 & India & 58 & 0.03 \\
Top 20 countries for & 12 & Portugal & 55 & 0.01 \\
marine econometrics & 18 & Sweden & 51 & 0.07 \\
publications from & 19 & Brazil & 47 & 0.02 \\
1996 to 2018 & 13 & Norway & 46 & 0.24 \\
& 14 & South Africa & 44 & 0.08 \\
& 20 & South Korea & 41 & 0.01 \\
\end{tabular}

Figure 11 .

Cooperation network diagram of marine econometrics research institutions

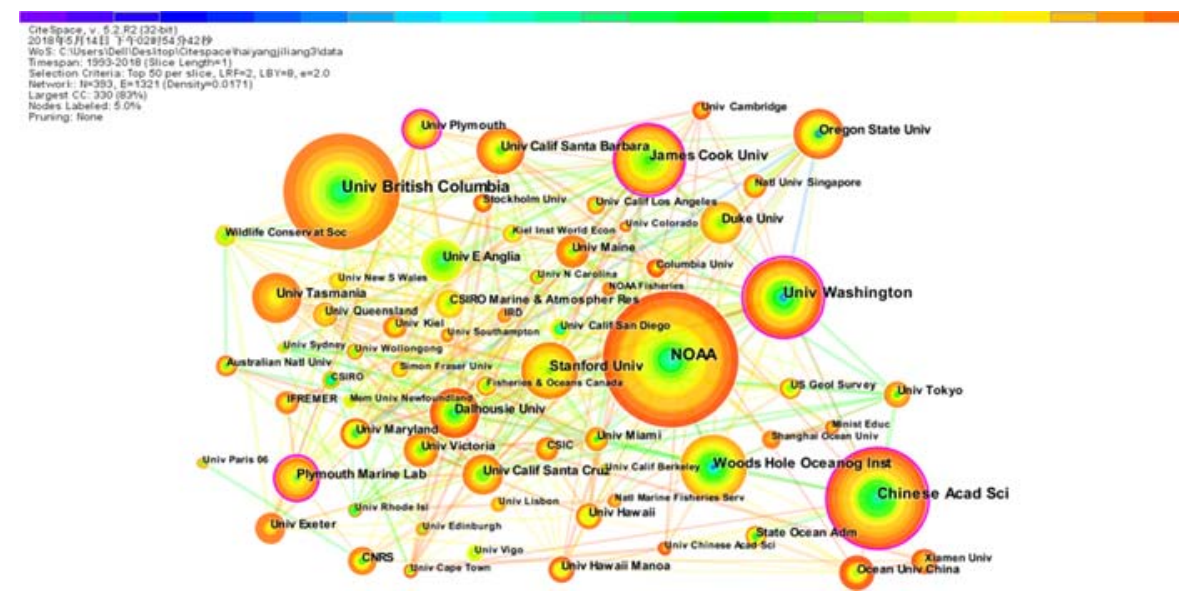

The size of the node circle in Figure 11 indicates the number of documents sent by the organization. The more nodes in the map, the larger the number of nodes in the map, and the connection between the nodes and other nodes indicates that the node has strong centrality, signifying that the mechanism of cooperation with other institutions is relatively close, and academic interchanges are strong. It can be seen from Figure 11 that between 1996 and 2018, there were many institutions that produced scholarly studies on ocean economics internationally, and the interchanges between institutions were relatively close. The top 20 research institutions with higher frequency in the literature analysis are summarized in Table IV.

Table IV lists the top 20 organizations with the largest number of documents published, and the USA has the maximum number of institutions (11), accounting for 55 percent of 


\begin{tabular}{|c|c|c|c|c|}
\hline Rank & Institution & Country & Publication number & mational \\
\hline 1 & NOAA & USA & 79 & econometrics \\
\hline 2 & Univ British Columbia & Canada & 67 & \\
\hline 3 & Chinese Acad Sci & People's Republic of China & 59 & \\
\hline 4 & Univ Washington & USA & 49 & \\
\hline 5 & James Cook Univ & Australia & 42 & \\
\hline 6 & Woods Hole Oceanog Inst & USA & 40 & 33 \\
\hline 7 & Stanford Univ & USA & 35 & \\
\hline 8 & Dalhousie Univ & Canada & 33 & \\
\hline 9 & Oregon State Univ & USA & 31 & \\
\hline 10 & Univ Tasmania & Australia & 31 & \\
\hline 11 & Univ Calif Santa Barbara & USA & 30 & \\
\hline 12 & Plymouth Marine Lab & England & 27 & \\
\hline 13 & Duke Univ & USA & 26 & \\
\hline 14 & Univ E Anglia & USA & 26 & \\
\hline 15 & Univ Calif Santa Cruz & USA & 24 & \\
\hline 16 & Ocean Univ China & People's Republic of China & 23 & Table IV. \\
\hline 17 & Univ Maryland & USA & 23 & Top 20 institutions for \\
\hline 18 & Univ Victoria & Canada & 22 & marine econometrics \\
\hline 19 & Univ Maine & USA & 21 & publications from \\
\hline 20 & Univ Plymouth & England & 21 & 1996 to 2018 \\
\hline
\end{tabular}

the total. The organization with the largest number of publications is NOAA, with a total of 79, followed by the University of British Columbia and the Chinese Academy of Sciences.

Further identifying the research institutions of countries or regions for marine econometrics research, describing the cooperative relationship between research institutions from a geographical point of view, a map of the geographical distribution of research institutions in different regions could be drawn, as shown in Figure 12.

In Figure 12, the white dots represent the research institutions, and the connections between them represent the cooperative relationship. Europe, North America, the southeastern part of Asia, the southeastern part of Australia and the eastern part of South America, have research

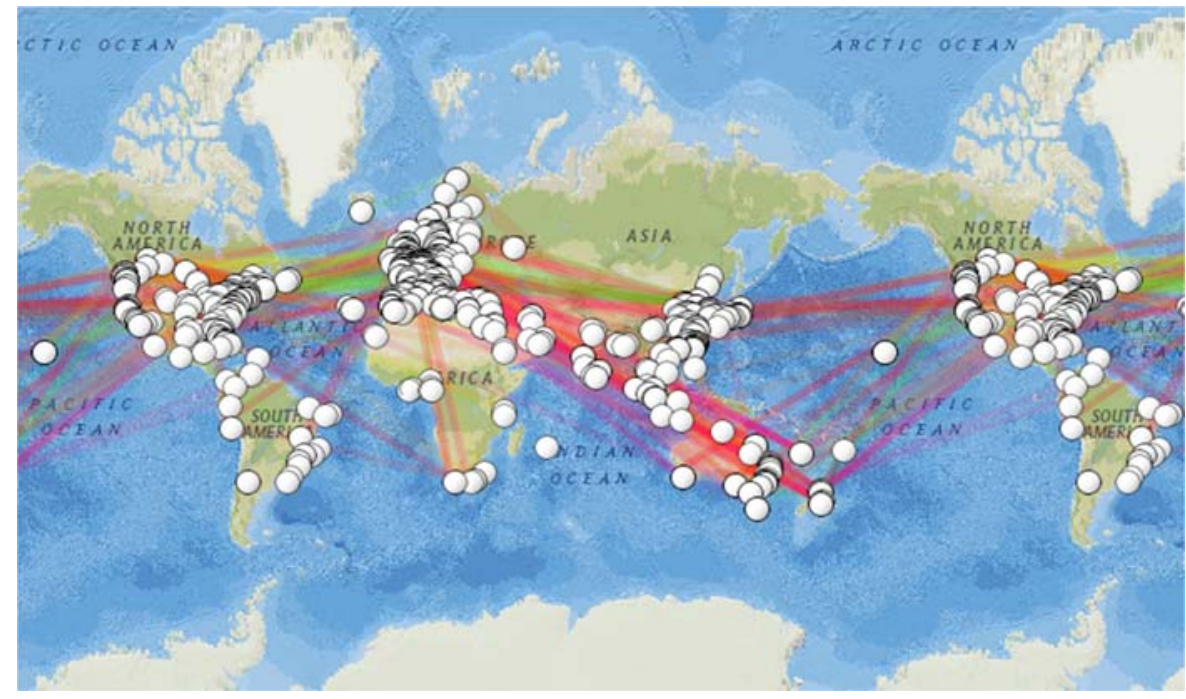

Figure 12. Geographical distribution cooperation network diagram of marine econometrics research institutions 
MAEM

1,1 institutions that are relatively densely distributed, indicating that there are a large number of institutions involved in marine economics research. In addition, only a few African institutions have participated in the study of ocean econometrics. In terms of partnerships, European research institutions work most closely with research institutions in North America and Australia. There is also cooperation between Asia and Europe and North America, but less so, and less closely. Research institutions in South America and Africa have fewer links with other regions and are thus relatively independent.

\subsection{Analysis of cited frequency of marine econometrics literature}

Table V lists the 1,489 observations regarding marine econometrics collected between 1996 and 2018, ranking the citations.

The top ten citations are listed in Table V (Cheung et al., 2010; Snyder and Kaiser, 2009; Deo and Naidu, 1999; Cheung and Sumaila, 2008; Widén et al., 2015; Klein et al., 2008; Reikard et al., 2011; Jin et al., 2003; Morrissey and O'Donoghue, 2013; Leite et al., 2014).

\begin{tabular}{|c|c|c|c|c|c|c|}
\hline Title & Countries & $\begin{array}{c}\text { Published } \\
\text { year }\end{array}$ & Source title & $\begin{array}{l}\text { Citation } \\
\text { frequency }\end{array}$ & $\begin{array}{l}\text { Research } \\
\text { methods }\end{array}$ & $\begin{array}{l}\text { Journal } \\
\text { impact } \\
\text { factor }\end{array}$ \\
\hline $\begin{array}{l}\text { Large-scale redistribution of } \\
\text { maximum fisheries catch } \\
\text { potential in the global ocean } \\
\text { under climate change }\end{array}$ & England & 2010 & $\begin{array}{l}\text { Global } \\
\text { change } \\
\text { biology }\end{array}$ & 347 & $\begin{array}{l}\text { Regression } \\
\text { analysis }\end{array}$ & 5.802 \\
\hline $\begin{array}{l}\text { Ecological and economic cost- } \\
\text { benefit analysis of offshore wind } \\
\text { energy }\end{array}$ & America & 2009 & $\begin{array}{l}\text { Renewable } \\
\text { energy }\end{array}$ & 124 & $\begin{array}{l}\text { Balanced } \\
\text { analysis }\end{array}$ & 4.357 \\
\hline $\begin{array}{l}\text { Real time wave forecasting using } \\
\text { neural networks }\end{array}$ & India & 1999 & $\begin{array}{l}\text { Ocean } \\
\text { engineering }\end{array}$ & 115 & $\begin{array}{l}\text { Machine } \\
\text { learning }\end{array}$ & 1.894 \\
\hline $\begin{array}{l}\text { Trade-offs between conservation } \\
\text { and socio-economic objectives in } \\
\text { managing a tropical marine } \\
\text { ecosystem }\end{array}$ & Canada & 2008 & $\begin{array}{l}\text { Ecological } \\
\text { economics }\end{array}$ & 62 & $\begin{array}{l}\text { Operations } \\
\text { research }\end{array}$ & 2.965 \\
\hline $\begin{array}{l}\text { Variability assessment and } \\
\text { forecasting of renewables: A } \\
\text { review for solar, wind, wave, and } \\
\text { tidal resources }\end{array}$ & Sweden & 2015 & $\begin{array}{l}\text { Renewable } \\
\text { and } \\
\text { sustainable } \\
\text { energy } \\
\text { reviews }\end{array}$ & 59 & $\begin{array}{l}\text { Time-series } \\
\text { analysis }\end{array}$ & 8.050 \\
\hline $\begin{array}{l}\text { Effectiveness of marine reserve } \\
\text { networks in representing } \\
\text { biodiversity and minimizing } \\
\text { impact to fishermen: a } \\
\text { comparison of two approaches } \\
\text { used in California }\end{array}$ & Australia & 2008 & $\begin{array}{l}\text { Conservation } \\
\text { letters }\end{array}$ & 58 & $\begin{array}{l}\text { System } \\
\text { dynamics }\end{array}$ & 7.020 \\
\hline $\begin{array}{l}\text { Forecasting ocean wave energy: } \\
\text { The ECMWF wave model and } \\
\text { time series methods }\end{array}$ & Denmark & 2011 & $\begin{array}{l}\text { Ocean } \\
\text { engineering }\end{array}$ & 39 & $\begin{array}{l}\text { Time-series } \\
\text { analysis }\end{array}$ & 1.894 \\
\hline $\begin{array}{l}\text { Linking economic and ecological } \\
\text { models for a marine ecosystem }\end{array}$ & America & 2003 & $\begin{array}{l}\text { Ecological } \\
\text { economics }\end{array}$ & 38 & $\begin{array}{l}\text { Input-output } \\
\text { analysis }\end{array}$ & 2.965 \\
\hline $\begin{array}{l}\text { The role of the marine sector in } \\
\text { the Irish national economy: An } \\
\text { input-output analysis }\end{array}$ & England & 2013 & Marine policy & 34 & $\begin{array}{l}\text { Input-output } \\
\text { analysis }\end{array}$ & 2.235 \\
\hline $\begin{array}{l}\text { Influence of proximity to an } \\
\text { urban center in the pattern of } \\
\text { contamination by marine debris }\end{array}$ & America & 2014 & $\begin{array}{l}\text { Marine } \\
\text { pollution } \\
\text { bulletin }\end{array}$ & 27 & $\begin{array}{l}\text { Regression } \\
\text { analysis }\end{array}$ & 3.146 \\
\hline
\end{tabular}

Table V. Top 10 documents cited by ocean econometrics 
Highly cited literature is generally an important reference with a groundbreaking role. Among the top ten studies cited, three were from the USA, two from the UK and the remaining five from Denmark, Australia, Canada, India and Sweden. Renewable and Sustainable Energy Reviews has the highest impact factor (8.05) among the top ten sources of marine econometrics literature, followed by Conservation Letters (7.02) and Global Change Biology (5.802). In the top ten marine econometrics studies cited in the frequency of citation figures, the focus is on the relationship between the marine economy and marine energy, marine ecology and marine ecological environment. The applied methodological analysis tools tend to use non-classical, modern and ocean econometrics methods.

\section{The ardent research direction of marine econometrics}

According to the above analysis, which shows that the research content of marine econometrics is quite extensive, the current research passion has mainly been concentrated in the coastal zone economy, marine economic sustainable development, marine resources, areas affected by marine disasters, marine science and technology contribution, and so forth.

\subsection{Coastal zone economic research}

The coastal zone is an important habitat for human beings and an important area for exploitation and utilization of resources. At present, many scholarly studies have been focusing on the sustainable development of the coastal economy, index system and quantitative evaluation model (Qin et al., 2015), coastal economics and the integration of sea and land development strategy (Zhu et al., 2018), the coastal zone's industrial structure and industrial competitiveness (Yan et al., 2015), the coastal zone's ecological value and natural disasters in terms of economic accounting (Brown and Hausner, 2017; Plomaritis et al., 2018), and ocean culture and ocean industries (Levine et al., 2015). Compared with the function of the land area evaluation model, specifically the study of the coastal zone economy, there are still some shortcomings in doing so, e.g., fuzzy research objects, systematic lack of research content and weak innovation within the research methods, all of which require further research and analysis.

He et al. (2014) studied China's economic development and changes in the coastal area (coastal zone) ecosystem using the Malmquist plots-Luenberger index model, and put forward suggestions regarding the sustainable development of China's marine economy. Wei et al. (2014) constructed the comprehensive bearing capacity model ICC, and calculated the sustainable development for the marine economy in both space and time ranges. Guo et al. (2017) applied the MPLAN input-output model to the economic relations of the Gulf-Coast region, studying the influence of Mississippi River and Alabama gulf-coast tourism on the regional economy.

\subsection{Research on sustainable development of marine economy}

The marine economy's sustainable development is based on the application and extension of the concept of sustainable development in the field of marine economics. There are complex systems engineering pertaining to marine conservation, utilization, repair, involving the marine resource, marine environment, marine ecology, marine culture, marine industry, marine science and technology, marine management, etc. At present, studies on sustainable development of the marine economy mainly use quantitative methods such as exponential analysis, comprehensive evaluation, principal component analysis, BP neural networks and general equilibrium models or system dynamics.

Pakalniete (2017) used the polynomial Logit model to study the preferences of Latvian citizens toward environmental improvement in the Baltic Sea's marine waters and to evaluate the economic benefits of environmental improvement. Tuhkanen et al. (2016) used a selective experimental method, a statistical modeling method, a non-linear utility function 
MAEM

1,1

analysis, etc., to study the three main pressures affecting the quality of Estonian marine environment factors, estimating the three kinds of relative economic value of stress factors changes, and evaluated the economic value of marine environmental improvement. Ronchi et al. (2002) used the ISSI index of welfare, environmental quality and resource utilization, proposing a combination algorithm and giving a global, comprehensive, non-dimensional index for comparison between different countries. Krelling et al. (2017) studied the economic impact of marine garbage pollution and evaluated the investment benefits of local authorities to prevent the beach garbage and the decline of tourism income.

\subsection{Effects of marine resources utilization on marine economy}

Since the formal coming into force of the "United Nations Convention on the Law of the Sea" in 1994, the world's maritime powers have adjusted their maritime strategic priorities. Marine resources are huge, with the characteristics of being clean, green, and renewable. In a narrow sense, marine resources refer to substances and energy that are directly related to the bodies of water comprising the seas, e.g., marine organisms, chemical elements in sea water and minerals on the sea floor. On the basis of the above categories, marine resources in a broad sense also include marine routes, seaports, bays, processing of aquatic resources, marine energy resources, marine landscape and space in the oceans (Wang and Bo, 2006; Johannes, 2002). The effective utilization of marine resources will be of great significance to the economic prosperity and sustainable development of all countries in the world.

Sugiawan et al. (2017) according to the empirical analysis of a global marine fishery using general methods of parameter modeling and panel data, they found that the economic growth after income reaches a certain level is beneficial to the sustainable development of a marine fishery. Wang et al. (2017) simplified Romer's natural resources and economic growth model under the restriction of land resources, and established the "end effect" model, including the AHP, entropy value method, parameter estimation, Solow model and panel data model. The results show that the faster the consumption of marine resources, the greater the resistance to the growth of the marine economy. Anneboina and Kavi Kumar (2017) used a stochastic frontier production function model to predict the technical efficiency of marine fishery production.

\subsection{The impact of marine disasters on the marine economy}

Marine disasters are disasters that occur in the sea or coast due to changes in the natural environment of the sea or meteorological conditions or other drastic changes (Xiao et al., 2015). There have been many studies on the impact, assessment, compensation and risk assessment of marine disasters in the world. At present, they mainly focus on the analysis and pre-evaluation of the impact of marine disasters on the marine economy and macroeconomic conditions.

Hidayah et al. (2018) adopted the multidimensional scaling method and selected five dimensions that involve ecology, economics, society, technology and systems to measure the impact of marine disasters on national economic development. Goda and De Risi (2018) proposed a probabilistic multi-hazard loss estimation method for coastal areas, and conducted a case study of large-scale earthquake activities that may occur in northeastern Japan, they concluded that the results of multi-hazard impact assessments are of great significance for reducing the risk of tsunami disaster losses. Yin et al. (2018) proposed a new multivariate gray disaster prediction model combining multivariate gray prediction with catastrophic prediction to avoid the shortcomings of traditional single-factor gray catastrophe prediction methods, improved the accuracy for simulation and prediction of marine hazards. Samarasekara et al. (2017) assessed the anti-tsunami capacity of coastal infrastructure by numerically simulating possible-to-develop, optimal mitigation measures. 
5. The developing trend of marine econometrics research

This study analyzes 1,489 collected articles related to marine econometrics from 1996 to 2018, through the literature map of marine econometrics based on post number, authors, keywords, and related discipline areas, related journals, countries (regions), research institutions and carding. Summarizing the above aspects revealed the study's status and development process regarding international marine econometrics, summed up the research focus of marine econometrics, and provided for further research in marine econometrics to provide referential cases.

\subsection{Research trends in marine econometrics}

With the successive implementation of marine strategic planning in coastal countries, case studies and in-depth research on marine econometrics issues have become more important, with greater demands and higher expectations being put forth for marine econometrics research. Such public policy also presents a development trend for the systematization of research categories (including macroscopic and microscopic ones), the diversification and cross-cutting research disciplines, and the modernization of research technologies.

5.1.1 Systematization of research areas. Non-classical macro-marine econometrics research have risen in demand, including the formulation of macro marine economic policies, the optimization of marine industry structure, land, and sea pooling and spatial layout, marine ecological environmental protection, and sustainable development, also is the important basis of states formulating plans for the development of the ocean. Non-classical macro-marine econometrics research involving time-varying characteristics and spatial structures for individual markets, individual enterprises, and individual products have become another new trend, including industrial clusters, industrial upgrading, new energy, carbon emission reduction, green development, technology innovation, and so forth.

5.1.2 Diversity of research disciplines. Marine econometrics is a multidisciplinary integrated system methodology. It includes system theory, information theory, control theory, synergism, mutation theory, system simulation (system dynamics, ASPEN, SWARM), general equilibrium theory, neural networks, etc. The current cross-disciplinary trend of marine econometrics research is becoming more obvious. For example, system simulation and experimental economics establish a simulation model that describes the system structure or behavioral process that has a certain logical or quantitative relationship, which will promote the construction and development of marine economic simulation experiments (or room) technology. These will reveal the evolution mechanism of marine economic systems, simulating the implementation effects of simulation policies, improving and expanding the input-output model of the marine economy, building a linkage model, and strengthening and improving the efficiency of policy analysis and research.

5.1.3 Modernization of research methods. At present, marine econometrics research uses a system of model type, orientation, structure, along with a particular data type, that are gradually being perfected and, thus, the characteristics of modern marine econometrics are becoming increasingly prominent. Examples include micro, non-parametric, time series, dynamic marine econometrics; e.g., micro-marine econometrics, panel data model, discrete data models, restricted data models, analysis of micro-marine economic information of individuals, families, enterprises, etc., the study of individual behavioral differences and their relationship with influencing factors, and so forth.

Systematic science, mathematics, computer science, physics, and other new methods, new technologies and collaborative, cross-applications that have been developed in recent years are now included. In particular, the latest methods and technologies have been
International marine econometrics 
MAEM

1,1

developed in related disciplines since 2000, e.g., artificial intelligence, data mining, machine learning, quantum technology, etc. - all of which are important methodological foundations for marine economics research, and they also need to be used as points of reference.

\subsection{Consideration of the problems involved with marine econometrics}

In recent years, marine leading industries, ocean science and technology contribution rates, endogenous growth problems, growth rate decomposition problems, structural optimization problems, industrial convergence problems, evolution mechanism problems, correlation effects problems, spatial layout problems and policy effects issues have emerged. Theoretical and empirical responses to marine econometrics research including quantitative economics are still needed:

(1) Traditional economics studies "quality" and quantitative economics studies "quantity." In the last decade or longer, some achievements have been made in the study of international marine econometrics, but the separation between it and other branches is still wide.

(2) The content and fields of marine econometrics research have been expanding rapidly but are also quite scattered. Due to the complex problems of the marine economy itself, the study of marine econometrics lacks enough sample data to support it, and even faces serious data bottleneck problems.

(3) Due to research environment differences and the academic backgrounds of marine economic researchers, there still remain non-standard problems in the application of research methods to marine econometrics research - even emerging as problems of abuse and misuse.

(4) Due to the official standard of sea-related management departments, the normative problems of the statistical data of the sea-related enterprises, and the scientific rationality of marine econometrics research teams, the available data are somewhat questionable. At present, phenomena in marine econometrics research are still relatively scattered and fragmented. There are still some low-level duplication problems in its study, and some differences in conclusions, some of which have risen to the level of disputes.

\subsection{Opportunities and challenges in marine econometrics}

The oceanic economic sample data is expanding, and modern measurement methods such as panel modeling, spatial measurement, non-linear non-parametric methods and DSGE have become important methodological tools for marine economic research. However, with the rapid evolution of information technology - and the sudden fall of the era of big data - the traditional methods of marine econometrics have been difficult to control the increasingly complex random quantitative relationships found in the modern marine economy.

First, the special structure of the evolutionary mechanism of marine economies, the irrational alienation of individual behaviors from marine economics, and the endogenous optimization of the correlation effect of the marine economy must be tamed.

Second, the lack of marine economic statistics and normative problems, quality diagnosis problems and singular mixing problems must be addressed as well.

Third, marine century, big data, marine disasters, wetland degradation, ecological protection and other issues should be better dealt with.

How to guide modern econometrics and the methodology of experimental economics to promote marine econometrics for research systems is crucial. Furthermore, popularizing 
and promoting marine econometrics in order to raise the level of application and overall development in the international marine econometrics for the future development of marine economy has become an important mission.

\section{Acknowledgments}

This research is supported by the National Social Science Fund Major Projects (14ZDB151); National Science Foundation of China under Grants (41701593, 71371098, 71571157); National Key Research and Development Program of China (2016YFC1402000); Public welfare industry research projects (201305034, 201405029); The Ministry of Education Philosophy and Social Sciences Development Report Cultivation Project (13JBGP005); General Financial Grant from the China Postdoctoral Science Foundation (2015M580611); Qingdao Postdoctoral Application Research Project (251); Fundamental Research Funds for the Central Universities (201613006, 201564031).

\section{References}

Anneboina, L.R. and Kavi Kumar, K.S. (2017), "Economic analysis of mangrove and marine fishery linkages in India”, Ecosystem Services, Vol. 24, pp. 114-123.

Barbier, E.B., Georgiou, I.Y., Enchelmeyer, B. and Reed, D.J. (2013), "The value of wetlands in protecting Southeast Louisiana from Hurricane Storm surges, multidisciplinary sciences", PLOS ONE, Vol. 8 No. 3, pp. 1-6.

Bhat, M.G. (2003), "Application of non-market valuation to the Florida keys marine reserve management", Journal of Environmental Management, Vol. 67 No. 4, pp. 315-325.

Brown, G. and Hausner, V.H. (2017), "An empirical analysis of cultural ecosystem values in coastal landscapes”, Ocean \& Coastal Management, Vol. 142, pp. 49-60.

Cao, Z.X., Ren, D.M., Wang, W.R. and Zhao, M.Y. (2005), "Analysis on structural improvement of regional marine economy”, Human Geography, Vol. 6, pp. 29-33.

Cheung, W.W.L. and Sumaila, U.R. (2008), "Trade-offs between conservation and socio-economic objectives in managing a tropical marine ecosystem", Ecological Economics, Vol. 66 No. 1, pp. 193-210.

Cheung, W.W.L., Lam, V.W.Y., Sarmiento, J.L., Kearney, K., Watson, R.E.G., Zeller, D. and Pauly, D. (2010), "Large-scale redistribution of maximum fisheries catch potential in the global ocean under climate change", Global Change Biology, Vol. 16 No. 1, pp. 24-35.

Deo, M.C. and Naidu, C.S. (1999), "Real time wave prediction using neural networks", Ocean Engineering, Vol. 26 No. 3, pp. 191-203.

Di, Q.B., Xu, D.S. and Zhou, L.P. (2012), "Study on dynamics model of marine economic sustainable development based on STELLA software", Ocean Development and Management, Vol. 3, pp. 90-94.

Feng, Y.H. and Du, Y.H. (2014), "The analysis of the grey correlation degree of Ningbo marine economic development and finance", Modern Business Trade Industry, Vol. 26, pp. 128-130.

Goda, K. and De Risi, R.D. (2018), "Multi-hazard loss estimation for shaking and tsunami using stochastic rupture sources", International Journal of Disaster Risk Reduction, Vol. 28, pp. 539-554.

Gröger, J.P., Missong, M. and Rountree, R.A. (2011), "Analyses of interventions and structural breaks in marine and fisheries time series: detection of shifts using iterative methods", Ecological Indicators, Vol. 11 No. 5, pp. 1084-1092.

Guo, Z., Robinson, D. and Hite, D. (2017), "Economic impact of Mississippi and Alabama Gulf coast tourism on the regional economy", Ocean \& Coastal Management, Vol. 145, pp. 52-61.

He, Q., Bertness, M.D., Bruno, J.F., Li, B., Chen, G., Coverdale, T.C., Altieri, A.H., Bai, J., Sun, T., Pennings, S.C., Liu, J., Ehrlich, P.R. and Cui, B. (2014), "Economic development and coastal ecosystem change in China”, Scientific Reports, Vol. 4, p. 5995. 
MAEM

1,1

Hidayah, Z., Rosyid, D.M. and Armono, H.D. (2018), "Sustainability analysis of coastal management in the madura strait", Applied Mechanics and Materials, Vol. 874, pp. 10-17.

Jiang, T.M. (1990), Research on China's Marine Regional Economy, Maritime Press, Beijing.

Jin, D., Hoagland, P. and Morin Dalton, T.M. (2003), "Linking economic and ecological models for a marine ecosystem", Ecological Economics, Vol. 46 No. 3, pp. 367-385.

Johannes, R.E. (2002), "The renaissance of community-based marine resource management in Oceania", Annual Review of Ecology and Systematics, Vol. 33 No. 1, pp. 317-340.

Klein, C.J., Steinback, C., Scholz, A.J. and Possingham, H.P. (2008), "Effectiveness of marine reserve networks in representing biodiversity and minimizing impact to fishermen: a comparison of two approaches used in California", Conservation Letters, Vol. 1 No. 1, pp. 44-51.

Krelling, A.P., Williams, A.T. and Turra, A. (2017), "Differences in perception and reaction of tourist groups to beach marine debris that can influence a loss of tourism revenue in coastal areas", Marine Policy, Vol. 85, pp. 87-99.

Lee, A.H.I., Chen, H.H. and Kang, H.Y. (2017), "A conceptual model for prioritizing dam sites for tidal energy sources”, Ocean Engineering, Vol. 137, pp. 38-47.

Leite, A.S., Santos, L.L., Costa, Y. and Hatje, V. (2014), "Influence of proximity to an urban center in the pattern of contamination by marine debris", Marine Pollution Bulletin, Vol. 81 No. 1, pp. 242-247.

Levine, A.S., Richmond, L. and Lopez-Carr, D. (2015), "Marine resource management: culture, livelihoods, and governance", Applied Geography, Vol. 59, pp. 56-59.

Li, J.K., Zhang, J., Gong, L.T. and Miao, P. (2015), "Research on the total factor productivity and decomposition of Chinese coastal marine economy: based on DEA-Malmquist index", Journal of Coastal Research, Vol. 73, pp. 283-289.

Liu, B.Q., Xu, M., Wang, J. and Xie, S.M. (2017), "Regional disparities in China's marine economy", Marine Policy, Vol. 82, pp. 1-7.

Moller, R.M. and Fitz, J. (1994), Economic Assessment of Ocean Dependent Activities, California Research Bureau, Sacramento, CA.

Morrissey, K. and O'Donoghue, C. (2013), "The role of the marine sector in the Irish national economy: an input-output analysis", Marine Policy, Vol. 37, pp. 230-238.

Nursey-Bray, M., Magnusson, A., Bicknell, N., Magnusson, M., Morison, J. and Sullivan, A. (2018), "Adapting to change: prioritising management for the future of the marine scalefish fishery", Marine Policy, Vol. 95, pp. 153-165.

Pakalniete, K. (2017), "Juris Aigars, Miko laj Czajkowski, Understanding the distribution of economic benefits from improving coastal and marine ecosystems", Science of the Total Environment, Vols 584-585, pp. 29-40.

Plomaritis, T.A., Costas, S. and Ferreira, Ó. (2018), "Use of a bayesian network for coastal hazards, impact and disaster risk reduction assessment at a coastal barrier (Ria Formosa, Portugal)", Coastal Engineering, Vol. 134, pp. 134-147.

Pontecorvo, G., Wilkinson, M., Anderson, R. and Holdowsky, M. (1980), "Contribution of the ocean sector to the US economy”, Science, Vol. 208 No. 4447, pp. 1000-1006.

Pugh, D. (2008), Socio-Economic Indicators of Marine - Related Activities in the UK Economy, The Crown Estate, London.

Pugh, D. and Skinner, L. (1996), "An analysis of marine-related activities in the UK economy and supporting science and technology", Information Document No. 5, Southampton: Inter-Agency Committee for Marine Science and Technology (IACMST) SOC.

Pugh, D. and Skinner, L. (2002), "A new analysis of marine-related activities in the UK economy with supporting science and technology", IACMST Information Document No. 10, The Inter-Agency Committee on Marine Science and Technology, Southampton Oceanography Centre. 
Qin, X., Sun, C. and Zou, W. (2015), "Quantitative models for assessing the human-ocean system's sustainable development in coastal cities: the perspective of metabolic-recycling in the Bohai sea ring area, China", Ocean \& Coastal Management, Vol. 107 No. 2, pp. 46-58.

Reikard, G., Pinson, P. and Bidlot, J.R. (2011), "Forecasting ocean wave energy: the ECMWF wave model and time series methods", Ocean Engineering, Vol. 38 No. 10, pp. 1089-1099.

Ronchi, E., Federico, A. and Musmeci, F. (2002), "A system oriented integrated indicator for sustainable development in Italy”, Ecological Indicators, Vol. 2 Nos 1-2, pp. 197-210.

International marine econometrics

Rorholm, N. (1967), "Economic impact of marine-oriented activities: a study of the southern new england marine region", University of Rhode Island, Kingston, Departmentof Food and Resource Economics.

Samarasekara, R.S.M., Sasaki, J., Esteban, M. and Matsuda, H. (2017), “Assessment of the co-benefits of structures in coastal areas for tsunami mitigation and improving community resilience in Sri Lanka”, International Journal of Disaster Risk Reduction, Vol. 23, pp. 80-92.

Snyder, B. and Kaiser, M.J. (2009), "Ecological and economic cost-benefit analysis of offshore wind energy”, Renewable Energy, Vol. 34 No. 6, pp. 1567-1578.

Sugiawan, Y., Islam, M. and Managi, S. (2017), “Global marine fisheries with economic growth”, Munich Personal RePEc Archive.

Tuhkanen, H., Piirsalu, E., Nõmmann, T., Karlõševa, A., Nõmmann, S., Czajkowski, M. and Hanley, N. (2016), "Valuing the benefits of improved marine environmental quality under multiple stressors", The Science of the Total Environment, Vols 551-552, pp. 367-375.

Wang, M. and Bo, L.V. (2006), "The causes and strategies of loss of China's ocean resource assets", Resources Science, Vol. 28 No. 5, pp. 102-107.

Wang, Z.W., Lu, X.F. and Han, Z.L. (2017), "Marine resources constraint and China's marine economic growth: metrology analysis based on marine resources 'Tail Drag'", Scientia Geographica Sinica, Vol. 37 No. 10, pp. 1497-1506.

Wei, C., Guo, Z.Y., Wu, J. and Ye, S. (2014), "Constructing an assessment indices system to analyze integrated regional carrying capacity in the coastal zones - a case in Nantong", Ocean \& Coastal Management, Vol. 93 No. 18, pp. 51-59.

Widén, J., Carpman, N., Castellucci, V., Lingfors, D., Olauson, J., Remouit, F., Bergkvist, M., Grabbe, M. and Waters, R. (2015), "Variability assessment and forecasting of renewables: a review for solar, wind, wave and tidal resources", Renewable and Sustainable Energy Reviews, Vol. 44, pp. 356-375.

Xiao, Y.B., Fu, X., Ng, A.K.Y. and Zhang, A. (2015), "Port investments on coastal and marine disasters prevention: economic modeling and implications", Transportation Research Part B: Methodological, Vol. 78, pp. 202-221.

Yan, X., Yan, L., Yao, X. and Liao, M. (2015), "The marine industrial competitiveness of blue economic regions in China”, Marine Policy, Vol. 62, pp. 153-160.

Yin, K.D. and Li, X.D. (2011), "Assessment of the comprehensive strength of marine economy in 11 provinces and cities along the coast of China", Statistics and Decision, Vol. 3, pp. 85-89.

Yin, K.D. and Ma, J.H. (2010), "Research on China's marine economic fluctuation monitoring and early warning technology", Statistics and Decision, Vol. 21, pp. 43-46.

Yin, K.D., Liu, J., Jin, X. and Li, X. (2018), "Multivariate grey disaster prediction model based on catastrophe date matrix", Journal of Grey System, Vol. 30 No. 1, pp. 140-150.

Yuan, F., Lu, Y.Y. and Yu, T. (2013), "An empirical analysis of ocean economy employment effect based on MGM $(1,2)$ model”, Contemporary Economics, Vol. 4, pp. 96-99.

Zamani, A., Solomatine, D., Azimian, A. and Heemink, A. (2008), "Learning from data for wind-wave forecasting”, Ocean Engineering, Vol. 35 No. 10, pp. 953-962.

Zhang, Y.G. and Hu, Y.M. (1997), Liaoning Island Resource Development and Marine Industrial Layout, Liaoning Normal University Press, Dalian. 
MAEM

1,1

\section{Further reading}

Liu, C. and Zhang, K. (2013), "Industrial ecology and water utilization of the marine chemical industry: a case study of Hai Hua Group (HHG), China”, Resources, Conservation and Recycling, Vol. 70, pp. 78-85.

Yin, K.D., Huang, H.Z. and Yue, L.L. (2013), "New progress of China's marine econometric research", Chinese Fisheries Economics, Vol. 5, pp. 168-176.

\section{Corresponding author}

Li Xuemei can be contacted at: lixuemei@ouc.edu.cn

For instructions on how to order reprints of this article, please visit our website: 